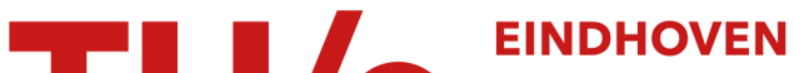 UNIVERSITY OF TECHNOLOGY
}

\section{Mobility and decay kinetics of charge carriers in photoexcited PCBM/PPV blends}

\section{Citation for published version (APA):}

Savenije, T. J., Kroeze, J. E., Wienk, M. M., Kroon, J. M., \& Warman, J. M. (2004). Mobility and decay kinetics of charge carriers in photoexcited PCBM/PPV blends. Physical Review B, 69(15), 155205-1/11. [155205]. https://doi.org/10.1103/PhysRevB.69.155205

DOI:

10.1103/PhysRevB.69.155205

Document status and date:

Published: 01/01/2004

\section{Document Version:}

Publisher's PDF, also known as Version of Record (includes final page, issue and volume numbers)

\section{Please check the document version of this publication:}

- A submitted manuscript is the version of the article upon submission and before peer-review. There can be important differences between the submitted version and the official published version of record. People interested in the research are advised to contact the author for the final version of the publication, or visit the $\mathrm{DOI}$ to the publisher's website.

- The final author version and the galley proof are versions of the publication after peer review.

- The final published version features the final layout of the paper including the volume, issue and page numbers.

Link to publication

\section{General rights}

Copyright and moral rights for the publications made accessible in the public portal are retained by the authors and/or other copyright owners and it is a condition of accessing publications that users recognise and abide by the legal requirements associated with these rights.

- Users may download and print one copy of any publication from the public portal for the purpose of private study or research.

- You may not further distribute the material or use it for any profit-making activity or commercial gain

- You may freely distribute the URL identifying the publication in the public portal.

If the publication is distributed under the terms of Article 25fa of the Dutch Copyright Act, indicated by the "Taverne" license above, please follow below link for the End User Agreement:

www.tue.nl/taverne

Take down policy

If you believe that this document breaches copyright please contact us at:

openaccess@tue.nl

providing details and we will investigate your claim. 


\title{
Mobility and decay kinetics of charge carriers in photoexcited PCBM/PPV blends
}

\author{
Tom J. Savenije, ${ }^{1, *}$ Jessica E. Kroeze, ${ }^{1}$ Martijn M. Wienk, ${ }^{2, \dagger}$ Johannes M. Kroon, ${ }^{2}$ and John M. Warman ${ }^{1}$ \\ ${ }^{1}$ Radiation Chemistry Department, Interfaculty Reactor Institute, Delft University of Technology, Mekelweg 15, \\ 2629 JB DELFT, The Netherlands \\ ${ }^{2}$ ECN Solar Energy, P.O. Box 1, 1755 ZG Petten, The Netherlands
}

(Received 15 September 2003; published 15 April 2004)

\begin{abstract}
The transient photoconductivity of blends of a highly soluble C60 derivative (PCBM) and a dialkoxyphenylene-vinylene polymer (MDMO-PPV) has been studied using the electrodeless flash-photolysis timeresolved microwave conductivity technique (FP-TRMC). Films approximately $100 \mathrm{~nm}$ thick on a quartz substrate were prepared by spin-coating PCBM/PPV solutions with PCBM weight fractions ( $\left.W_{\text {PCBM }}\right)$ from 0.2 to 0.95 . For all blends, the wavelength dependence of the photoconductivity in the range $420-700 \mathrm{~nm}$ closely resembled the photon attenuation spectrum, indicating that photoexcitation of both components contributes to mobile charge carrier formation. The product of the quantum yield for charge separation $\phi$ and the sum of the charge carrier mobilities $\Sigma \mu$ was determined from the maximum (end-of-pulse) value of the transient photoconductivity. On excitation at $500 \mathrm{~nm}, \phi \Sigma \mu$ remained almost constant in going from $W_{\mathrm{PCBM}}=0.2$ to 0.6 with an average value of $0.6 \times 10^{-3} \mathrm{~cm}^{2} / \mathrm{V} \mathrm{s}$. Above $W_{\mathrm{PCBM}}=0.6, \phi \Sigma \mu$ increased dramatically, reaching a maximum value of $83 \times 10^{-3} \mathrm{~cm}^{2} / \mathrm{V} \mathrm{s}$ for $W_{\mathrm{PCBM}}=0.85$. This effect is attributed to the occurrence of phase separation above $W_{\text {PCBM }}=0.6$ and to the resulting formation of highly mobile electrons within PCBM-rich aggregates. The much lower value of $\phi \Sigma \mu$ observed below $W_{\mathrm{PCBM}}=0.6$ is assigned mainly to mobile holes within the polymer component of the blend. Possible explanations for the decrease in $\phi \Sigma \mu$ with increasing light intensity, found for all blend compositions, are discussed.
\end{abstract}

DOI: 10.1103/PhysRevB.69.155205 PACS number(s): 72.20.Jv, 73.61.Ph, 73.61.Wp, 73.50.Pz

\section{INTRODUCTION}

During the last decade a tremendous number of studies has been carried out to find low-cost alternatives to crystalline silicon for application in flexible photovoltaic devices. Organic materials such as conjugated polymers and fullerene derivatives seem to be promising candidates due to their low processing costs and their mechanical and chromatic flexibility. ${ }^{1-3}$ One of the major drawbacks associated with the use of conjugated polymers originates from the fact that only near the interface between the electron donor and electron acceptor material an absorbed photon efficiently leads to the formation of mobile charge carriers. ${ }^{4,5}$ Since in most of these polymers the distance the excitation energy can travel is limited to only several nanometers, ${ }^{6-8}$ the efficiencies of solar cells based on smooth bilayers of an electron donor and acceptor, analogous to a $p / n$ junction, have remained poor. ${ }^{4,5,8}$

A breakthrough in the realization of efficient all-organic solar cells was the development of the so-called "bulk heterojunction," ${ }^{9}$ in which a blend of donor and acceptor molecules forms a three-dimensional network. In this way an absorbed photon is always close to an interface. This approach therefore overcomes the problem of the limited absorption of light near the interface of a conventional bilayer device. Ultrafast light-induced charge transfer in a blend of a conjugated polymer and a fullerene derivative has been shown to yield long-lived charge carriers. ${ }^{10}$ Power efficiencies over $2.5 \%$ under AM1.5 irradiation have been reported for plastic solar cells prepared using a blend of the conjugated polymer poly[2-methoxy-5-( $3^{\prime}, 7^{\prime}$-dimethyloctyloxy)-p-phenylene vinylene] (MDMO-PPV) and the fullerene derivative, $[6,6]$-phenyl $\mathrm{C}_{61}$-butyric acid methyl ester (PCBM). ${ }^{11-14}$

In addition to light absorption and charge carrier generation, the transport of charge to the electrodes is an essential process for an efficient photovoltaic cell. While it is not completely understood for bulk heterojunctions whether the charge carriers move solely by their diffusional motion or that an internal electrical field causes the charges to drift to the electrodes, in either case a high diffusion coefficient or mobility for both positive and negative charge carriers will be beneficial for charge collection. ${ }^{9,15}$ Numerous studies have been devoted to understanding the fundamentals of charge transport of both individual compounds. For dialkoxy substituted poly(phenylene-vinylene) a zero-field mobility value for holes in thin films of $5 \times 10^{-7} \mathrm{~cm}^{2} / \mathrm{V}$ s has been reported. ${ }^{16}$ Studies with high probing frequencies, however, have yielded much higher mobility values, i.e., 1 $\times 10^{-4} \mathrm{~cm}^{2} / \mathrm{V} \mathrm{s} .{ }^{17,18}$ For fullerene derivatives electron mobilities given in the literature are close to $0.1 \mathrm{~cm}^{2} / \mathrm{V} \mathrm{s}$ for bulk materials, ${ }^{19,20}$ and $2 \times 10^{-3} \mathrm{~cm}^{2} / \mathrm{V}$ s for PCBM thin films. ${ }^{21}$

Despite the fact that the transport properties of the charge carriers are thought to limit the efficiency of photovoltaic cells produced from these materials, ${ }^{22}$ mobility studies on bulk heterojunctions are rare. ${ }^{21}$ In this work we study the transport properties in thin films of blends of MDMO-PPV and PCBM, which were photoexcited with a nanosecond visible laser pulse producing free charge carriers. The (nanosecond) change in conductivity was measured using the timeresolved microwave conductivity technique (TRMC), which relieves us of having to apply electrodes. Since this method cannot discriminate between the contribution of positive and negative charge carriers, only the sum of the mobilities $\Sigma \mu$ 
TABLE I. Physical properties of the PCBM/PPV blend films studied; see the text for a definition of the parameters listed.

\begin{tabular}{cccccc}
\hline \hline $\begin{array}{c}\text { Sample } \\
W_{\text {PCBM }}\end{array}$ & $L(\mathrm{~nm})$ & OD $(500)$ & $\alpha\left(10^{6} \mathrm{~m}^{-1}\right)$ & $\begin{array}{c}\Lambda_{h_{v}} \\
(\mathrm{~nm})\end{array}$ & $\begin{array}{c}\phi \Sigma \mu^{\mathrm{a}} \\
\left(10^{-3} \mathrm{~cm}^{2} / \mathrm{V} \mathrm{s}\right)\end{array}$ \\
\hline 0 & 56 & 0.466 & 19.2 & 52 & 0.14 \\
0.2 & 53 & 0.372 & 16.1 & 62 & 0.42 \\
0.4 & 68 & 0.300 & 10.2 & 99 & 0.32 \\
0.6 & 80 & 0.310 & 8.92 & 112 & 0.93 \\
0.7 & 86 & 0.258 & 6.91 & 145 & 8.7 \\
0.75 & 57 & 0.161 & 6.50 & 154 & 15 \\
0.8 & 80 & 0.185 & 5.32 & 188 & 45 \\
0.85 & 150 & 0.297 & 4.56 & 220 & 83 \\
0.9 & 265 & 0.413 & 3.59 & 279 & 66 \\
0.95 & 150 & 0.190 & 2.92 & 343 & 65 \\
1 & 56 & 0.067 & 2.77 & 361 & 0.02 \\
\hline \hline
\end{tabular}

${ }^{a}$ Values measured at $500 \mathrm{~nm}$ for the lowest intensity used.

can be calculated from the change in conductivity.

So far only a limited number of studies has been devoted to evaluating the effect on the photovoltaic properties of changing the ratio of the individual compounds in the heterojunction. ${ }^{9,23-25}$ From these works the highest efficiencies were obtained for a fullerene weight fraction $\left(W_{\text {PCBM }}\right)$ of approximately 0.8 . Brabec et al. studied the effect on the short circuit current of introducing a conventional polymer (polystyrene) into the blend, in an attempt to determine the percolation threshold. ${ }^{26}$ However, the effect of the blend ratio on the charge transport properties of charge carriers within the blend remains unclear.

Since by using the TRMC method no electrodes have to be applied, we can systematically change the fullerene weight fraction within the blend, without the problems associated with, e.g., shunt contacts. By calculating $\Sigma \mu$ of the charge carriers of samples with different $W_{\text {PCBM }}$ we can determine the relation between the mobility and $W_{\mathrm{PCBM}}$ and determine the optimum PCBM/MDMO-PPV ratio from the mobility point of view. Also the wavelength-dependent photoconductivity, the so-called "action spectrum," is measured. By comparing the action spectrum with the optical absorption of the blend the wavelength dependence of the quantum yield for charge separation can be determined, which may reveal possible differences between photoinduced hole and electron transfer processes.

\section{EXPERIMENTAL}

The fullerene derivative $[6,6]$-phenyl- $\mathrm{C}_{61}$-butyric acid methyl ester (PCBM) and poly[2-methoxy-5$\left(3^{\prime}, 7^{\prime}\right.$-dimethyl-octyloxy)- $p$-phenylene vinylene] (MDMOPPV) were obtained from Professor J.C. Hummelen, Groningen University, and Covion, respectively, and were used as received. Solutions in 1,2-dichlorobenzene with PCBM weight fractions, $W_{\mathrm{PCBM}}$, varying from 0.2 to 0.95 were spin-coated in air at $2000 \mathrm{rpm}$ onto $1 \mathrm{~mm}$ thick, 12 $\times 25 \mathrm{~mm}^{2}$ quartz substrates. The thickness $L$ of the resulting films was measured using a Dektak 3ST step profiler. The measured thicknesses of all of the layers studied together with the corresponding $W_{\text {PCBM }}$ values are listed in Table I.

A Perkin Elmer "Lambda 900" UV/Vis/NIR spectrophotometer fitted with an integrating sphere ("Labsphere") was used to measure the fraction of incident light reflected and transmitted by the sample, $F_{R}$ and $F_{T}$, respectively. These values were used to determine the optical density OD, which is defined by the relationships

$$
\begin{aligned}
F_{T} & =\left(1-F_{R}\right) 10^{-\mathrm{OD}} \\
& =\left(1-F_{R}\right) 10^{-\varepsilon c L} .
\end{aligned}
$$

In Eq. (2), $\varepsilon$ is the extinction coefficient of the absorbing entity and $c$ is its molar concentration. An alternative parameter, frequently used when discussing thin layers of solid materials, is the linear absorption coefficient $\alpha$, defined by

$$
F_{T}=\left(1-F_{R}\right) e^{-\alpha L} .
$$

As can be seen, $\alpha$ is related to the optical density and $\varepsilon$ by

$$
\alpha=\frac{\mathrm{OD} \ln 10}{L}=\varepsilon c \ln 10 .
$$

The optical densities and $\alpha$ values at $500 \mathrm{~nm}$, the wavelength most thoroughly investigated, including the corresponding penetration depths $\left(\Lambda_{h \nu}=1 / \alpha\right)$, are given for the different layers studied in Table I.

A parameter which is often more relevant than either the absorption coefficient or the optical density when making comparisons with photoconductivity transients is the fraction of incident photons actually attenuated within the layer, $F_{A}$,

$$
F_{A}=1-\left(F_{R}+F_{T}\right) .
$$

The wavelength dependence of $F_{A}$ is called here the "attenuation spectrum" to differentiate it from the "absorption spectrum," $\mathrm{OD}(\lambda)$.

The samples were mounted in an $X$-band microwave cavity at a position corresponding to a maximum in the electric field strength of the standing wave pattern at resonance (for details see Ref. 27). The sample could be illuminated via a grating in the copper end plate of the cavity which was covered and vacuum sealed with a quartz window. The iriscoupling hole of the cavity was sealed with a polyimide foil. The cavity was attached to a vacuum line and the air was replaced by a mixture of $10 \% \mathrm{SF}_{6}$ in $\mathrm{CO}_{2}$ at atmospheric pressure to scavenge any free electrons which might be ejected from the film by photoelectron emission. ${ }^{28}$

For photoexcitation in the visible, the third harmonic of a $Q$-switched Nd:YAG (yttrium aluminum garnet) laser ("Infinity 15-30," Coherent) was used to pump an optical parametric oscillator (OPO) yielding $3 \mathrm{~ns}$ full width at half maximum (FWHM) pulses continuously tunable from 420 to 700 $\mathrm{nm}$. The beam was expanded using $\mathrm{CaF}_{2}$ lenses to give a close to uniform intensity over a rectangular area of approximately $1 \times 2 \mathrm{~cm}^{2}$, close to the cross-sectional dimensions of the cavity and the sample. The integrated incident laser intensity, $I_{0}$ photons $/ \mathrm{cm}^{2}$ per pulse, was monitored by deflecting a small percentage of the light to the pyroelectric sensor 
of a Labmaster power meter (Coherent). The intensity could be attenuated using a series of metal-coated neutral-density filters (Melles Griot). In this way $I_{0}$ could be varied by more than four orders of magnitude from $6 \times 10^{11}$ to 1 $\times 10^{16}$ photons $/ \mathrm{cm}^{2}$ at $500 \mathrm{~nm}$.

Any photoinduced change in the conductance of the sample $\Delta G$ resulting from the formation of mobile charge carriers was monitored as a change in the power reflected by the cavity, $\Delta P / P$, using nanosecond time-response microwave circuitry and detection equipment described previously. ${ }^{29}$ Several single-shot conductivity transients could be averaged to improve the signal-to-noise ratio. The overall time response of $18 \mathrm{~ns}$ was determined mainly by the loaded quality factor of the cavity $Q_{L}$.

The change in microwave power is related to the change in conductance of the irradiated film by

$$
[\Delta P / P]=-K \Delta G .
$$

In Eq. (6), $\mathrm{K}$ is the sensitivity factor which can be derived from the resonance characteristics of the cavity and the dielectric properties of the medium; in the present work $K$ $=19 \times 10^{3} \mathrm{~S}^{-1}$. For a layer of thickness much smaller than the wavelength of the microwaves, as in the present case, $\Delta G$ is related to the conductivity at a depth $z$ within the layer, $\Delta \sigma(z)$, by

$$
\Delta G=\beta \int_{0}^{L} \Delta \sigma(z) \delta z .
$$

In Eq. (7), $\beta$ is the ratio between the broad and narrow inner dimensions of the waveguide and is equal to 2.08 for the $X$-band waveguide used. Substituting in Eq. (7) for $\Delta \sigma(z)$ $=e N(z) \Sigma \mu$, with $e$ the elementary charge, $N(z)$ the charge carrier pair concentration at depth $z$, and $\Sigma \mu$ the sum of the charge carrier mobilities, results in

$$
\Delta G=\beta e \sum \mu \int_{0}^{L} N(z) \delta z .
$$

If charge carriers are formed with an initial quantum yield $\phi_{0}$ and no decay occurs during the pulse, then the integral in Eq. (8) is equal to $I_{0} F_{A} \phi_{0}$ and the conductance change $\Delta G$ will be

$$
\Delta G_{0}=I_{0} F_{A} \beta e \phi_{0} \sum \mu .
$$

According to Eq. (9), the wavelength dependence of $\Delta G_{0} / I_{0}$ (the "photoconductivity action spectrum") should closely follow the attenuation spectrum, $F_{A}(\lambda)$, if $\phi_{0}$ is wavelength independent. Rearrangement of Eq. (9) leads to an expression for the product of the quantum yield and mobility of charge carriers in terms of the experimentally measured parameters $\Delta G, I_{0}$, and $F_{A}$,

$$
\phi_{0} \sum \mu=\frac{\Delta G_{0} / I_{0}}{F_{A} \beta e}
$$

Since mobile charge carriers are formed during the pulse and eventually decay via charge recombination and/or trap-

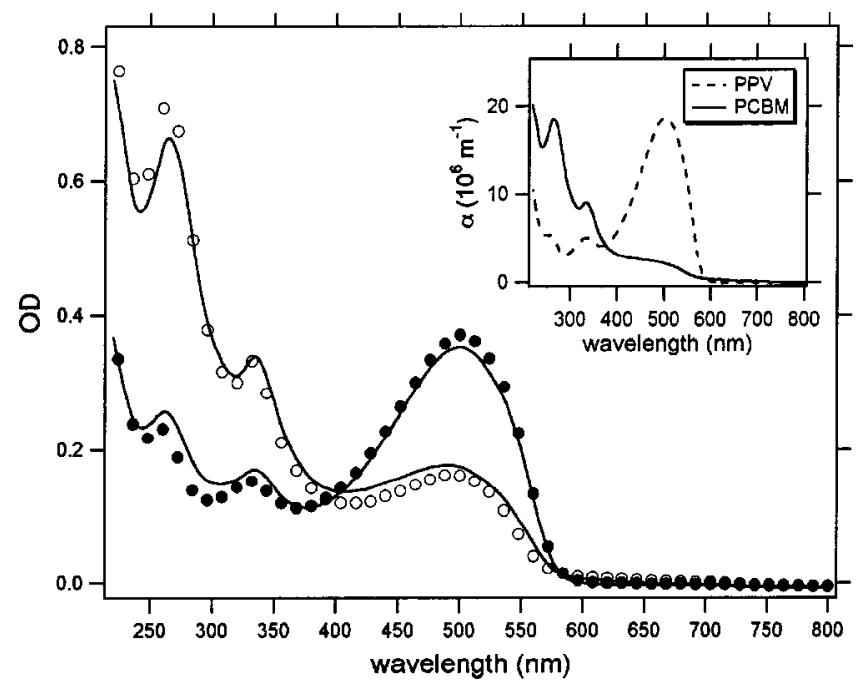

FIG. 1. Optical-absorption spectra of spin-coated films of PCBM/PPV blends with $W_{\text {PCBM }}=0.2, L=53 \mathrm{~nm}$ (full circles) and $W_{\text {PCBM }}=0.75, L=57 \mathrm{~nm}$ (open circles). Upper right inset: Absorption coefficients $\alpha$ for the separate components. The full lines in the main figure are reconstructed $\operatorname{OD}(\lambda)$ spectra based on the values of $\alpha$ for the individual components and the measured values of $W_{\mathrm{PCBM}}$ and $\mathrm{L}$.

ping, $\Delta G$ will be time dependent and the temporal form is referred to as a "photoconductivity transient," $\Delta G(t)$. If the decay occurs on a time scale much longer than the instrument response time, the "end-of-pulse" value of $\Delta G(t)$, $\Delta G_{\mathrm{EOP}}$, will be equal to $\Delta G_{0}$ and substitution in Eq. (10) will yield the true value of $\phi_{0} \Sigma \mu$. If, however, the decay of charge carriers occurs on a time scale comparable to the response time, the value of $\phi \Sigma \mu$ derived using $\Delta G_{\mathrm{EOP}}$ in Eq. (10) will be a lower limit to $\phi_{0} \Sigma \mu$, i.e.,

$$
\begin{gathered}
\phi \sum \mu=\frac{\Delta G_{\mathrm{EOP}} / I_{0}}{F_{A} \beta e} \\
\leqslant \phi_{0} \sum \mu .
\end{gathered}
$$

In studies of practical photovoltaic devices, the efficiency is usually related to the incident photon flux and given as the IPCE value, the "incident photon to current conversion efficiency." For a more ready comparison with the present FPTRMC measurements we have introduced the IPCSE parameter; the "charge separation efficiency per incident photon" with the symbol $\eta$. This is related to the quantum yield per absorbed photon simply by $\eta=\phi F_{A}$.

\section{RESULTS AND DISCUSSION}

\section{A. Optical absorption}

The optical-absorption spectra of spin-coated blend layers with $W_{\text {PCBM }}=0.20$ and 0.75 are shown in Fig. 1. Also shown in the inset are the wavelength dependencies of the absorption coefficients $\alpha$ of the separate components, PCBM and 


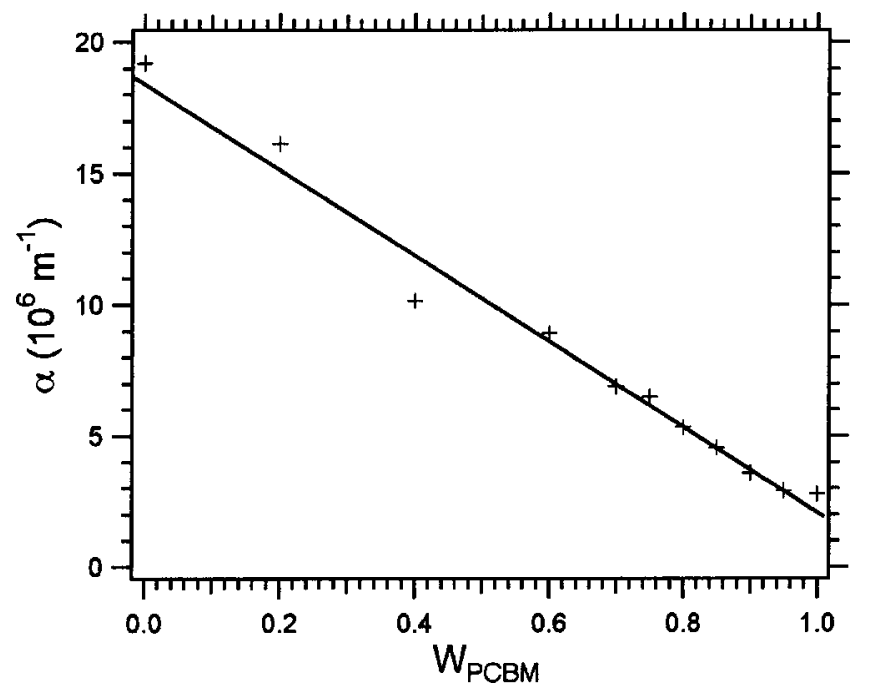

FIG. 2. The dependence of the absorption coefficients $\alpha$, determined from the measured optical densities and thicknesses of PCBM/PPV films on $W_{\text {PCBM }}$.

MDMO-PPV. If the components of a blend are noninteractive in the ground state, the overall optical density should be given by

$$
\mathrm{OD}=\left\{\frac{\alpha_{1} W_{1} \rho_{B}}{\rho_{1}}+\frac{\alpha_{2}\left(1-W_{1}\right) \rho_{B}}{\rho_{2}}\right\} L / \ln 10 .
$$

In Eq. (13), $W_{1}$ is the weight fraction of component $1, \rho_{1}$ and $\rho_{2}$ are the densities of the pure components 1 and 2, and $\rho_{B}$ is the density of the blend. Making the assumption that the densities of the individual components and the blends are closely similar for the present compounds leads to

$$
\mathrm{OD}=\left\{\alpha_{\mathrm{PPV}}+W_{\mathrm{PCBM}}\left(\alpha_{\mathrm{PCBM}}-\alpha_{\mathrm{PPV}}\right)\right\} L / \ln 10 .
$$

The full-line absorption spectra for the blends drawn in Fig. 1 were calculated using Eq. (14) with the individual wavelength dependencies of $\alpha_{\mathrm{PPV}}$ and $\alpha_{\mathrm{PCBM}}$ shown in the inset, together with the known weight fraction of PCBM in the solutions used for spin-coating, and the measured layer thicknesses of 53 and $57 \mathrm{~nm}$, respectively. The calculated spectra are seen to be in very good agreement with those actually measured. This good agreement, and particularly the absence of additional absorption bands in the blends, confirms that direct, Franck-Condon charge-transfer transitions between the components do not occur. The lack of ground state interaction between the components is further substantiated by the good linear dependence of the overall values of $\alpha$ on $W_{\text {PCBM }}$ measured at $500 \mathrm{~nm}$ shown in Fig. 2.

On the basis of the above, we conclude that the initial products of light absorption in the blends are the excited singlet states of the individual components of the mixture,

$$
\begin{gathered}
\mathrm{PCBM} \stackrel{{ }^{h \nu}}{\longrightarrow} \mathrm{PCBM}^{*} \quad(\text { reaction } \mathrm{A}), \\
\mathrm{PPV} \stackrel{{ }^{h \nu}}{\longrightarrow} \mathrm{PPV}^{*} \quad(\text { reaction } \mathrm{B}) .
\end{gathered}
$$

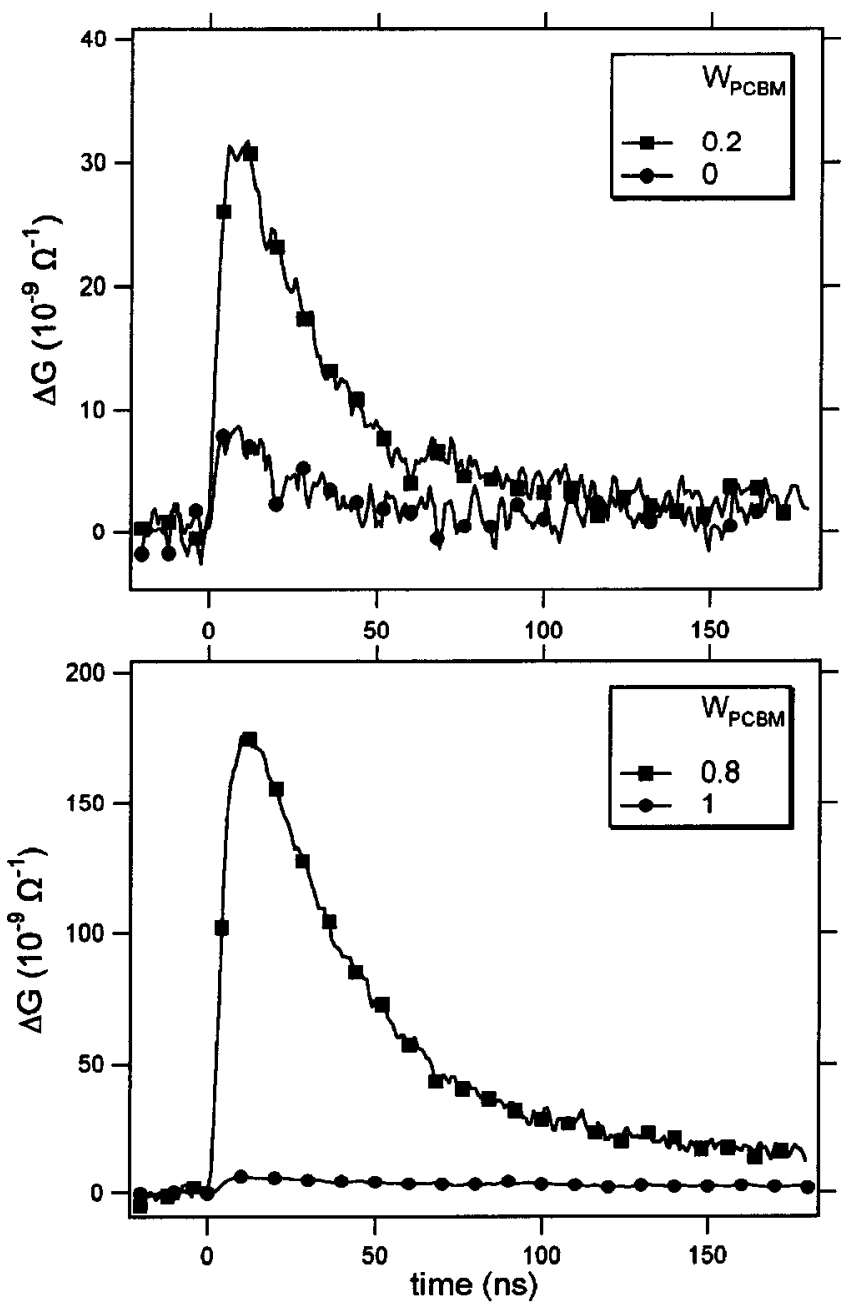

FIG. 3. Transient changes in the conductance on flashphotolysis at $500 \mathrm{~nm}$ of films of PCBM/PPV blends and PCBM and PPV alone. The upper and lower figures illustrate the effect of the addition of $20 \%$ of the second component to pure MDMO-PPV and pure PCBM, respectively.

If mobile charged species are formed this must therefore result from subsequent electron transfer between the components.

The fraction of photons absorbed by the PCBM component of a blend will be given by

$$
\Delta E_{\mathrm{PCBM}}=\frac{\alpha_{\mathrm{PCBM}} W_{\mathrm{PCBM}}}{\alpha_{\mathrm{PCBM}} W_{\mathrm{PCBM}}+\alpha_{\mathrm{PPV}}\left(1-W_{\mathrm{PCBM}}\right)} .
$$

Substitution for $\alpha_{\mathrm{PPV}}=19.2 \times 10^{6} \mathrm{tm}^{-1}$ and $\alpha_{\mathrm{PCBM}}=2.77$ $\times 10^{6} \mathrm{~m}^{-1}$ at $500 \mathrm{~nm}$ results in

$$
\Delta E_{\mathrm{PCBM}}=\left\{1+6.9\left(\frac{1}{W_{\mathrm{PCBM}}}-1\right)\right\}^{-1} .
$$

Therefore, even for $80 \%$ PCBM in the mixture, approximately two-thirds of the photons absorbed will initially result in photoexcitation of the PPV component at this wavelength. 


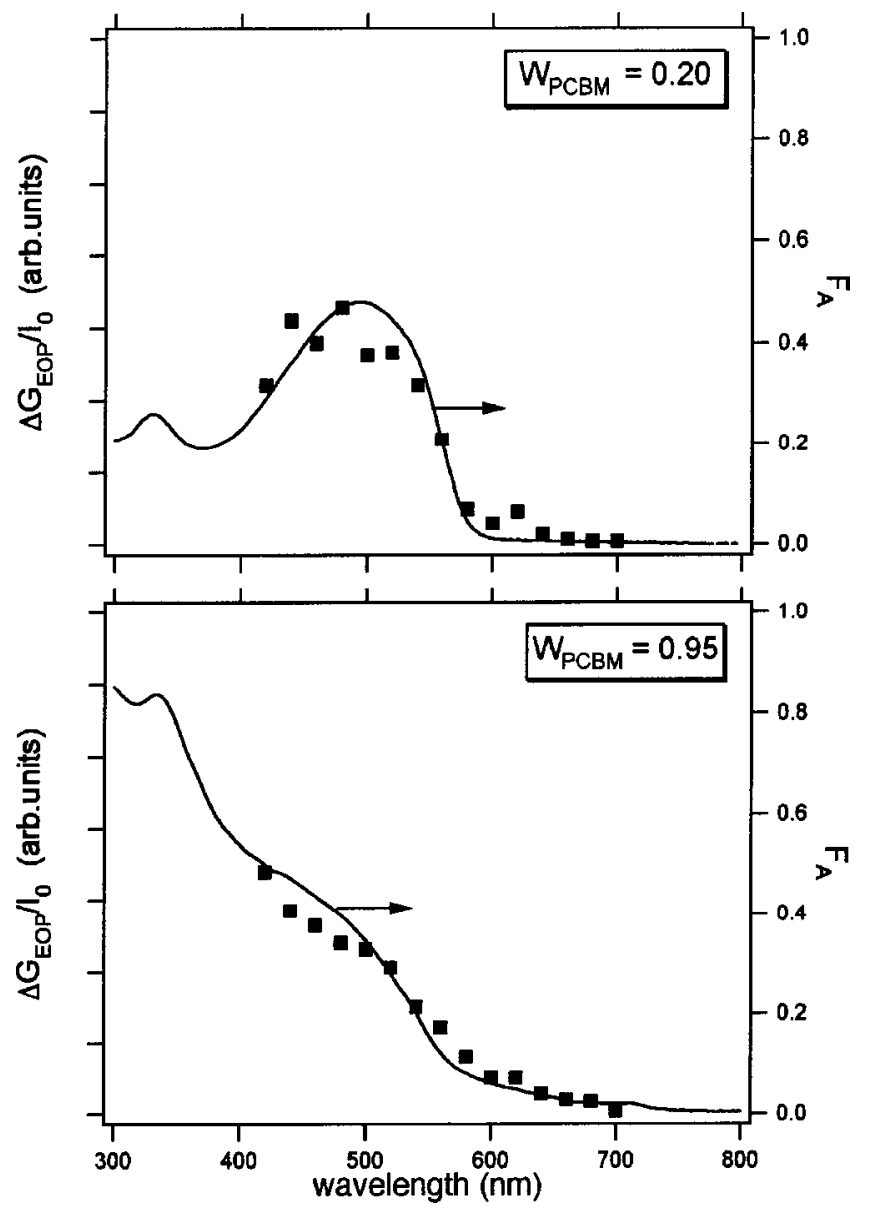

FIG. 4. The wavelength dependence of the maximum value of the photoconductivity transients $\Delta G_{\mathrm{EOP}}$ normalized by the integrated incident light intensity in the pulse for the values of $W_{\text {PCBM }}$ indicated. The full lines represent the optical attenuation spectra of the films.

\section{B. Photoconductivity transients and action spectra}

Examples of photoconductivity transients for films of PPV and PCBM alone, and for blends containing 20\% of the second component are shown in Figs. 3(a) and 3(b). In both cases the pure component displays only a relatively small photoconductivity but this increases substantially in the presence of the second component. This is particularly dramatic for the addition of $20 \%$ PPV to PCBM which on its own displays negligible photoconductive behavior. These qualitative observations confirm, therefore, that electron transfer between the components occurs, reactions $\mathrm{C}$ and $\mathrm{D}$, and that the charge on one or both of the radical ion species formed, $\mathrm{PPV}^{+}$and/or $\mathrm{PCBM}^{-}$, is mobile within the blend matrix,

$$
\begin{aligned}
& \mathrm{PPV}^{*}+\mathrm{PCBM} \longrightarrow \mathrm{PPV}^{+}+\mathrm{PCBM}^{-} \quad(\text { reaction } \mathrm{C}) \\
& \mathrm{PCBM}^{*}+\mathrm{PPV} \longrightarrow \mathrm{PCBM}^{-}+\mathrm{PPV}^{+} \quad(\text { reaction } \mathrm{D}) .
\end{aligned}
$$

The wavelength dependence of $\Delta G_{\mathrm{EOP}} / I_{0}$, for transients such as those in Figs. 3(a) and 3(b), are shown for blends with $W_{\mathrm{PCBM}}=0.2$ and 0.95 in Fig. 4. Reasonably good agreement is found between these photoconductivity action spec-

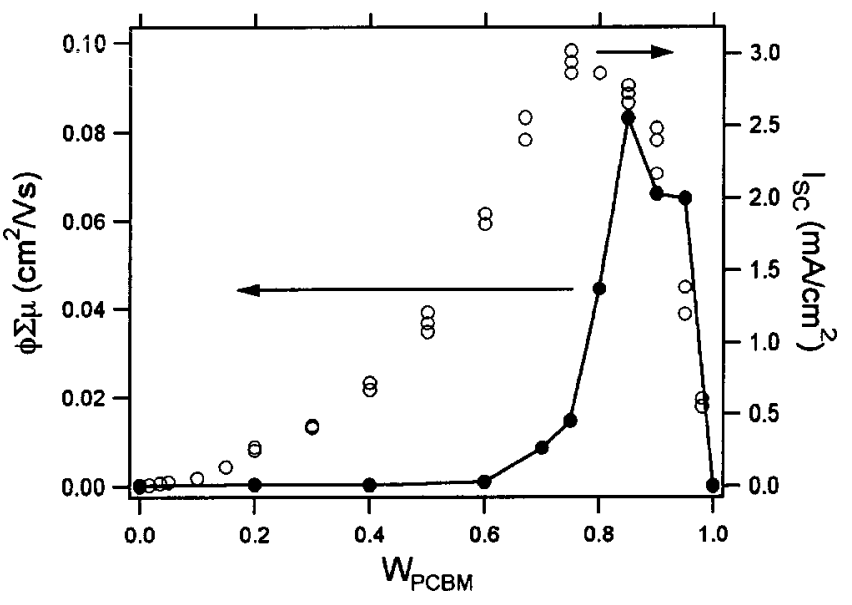

FIG. 5. The dependence on $W_{\text {PCBM }}$ of the values of $\phi \Sigma \mu$ derived on $500 \mathrm{~nm}$ irradiation for the lowest intensity used (closed circles). Also shown as open circles are the values obtained for the short-circuit current as a function of $W_{\mathrm{PCBM}}$ measured in photovoltaic device structures (data taken from Refs. 24 and 25).

tra and the attenuation spectra, $F_{A}(\lambda)$, given as full lines in the figure. The good agreement for the extremes of $20 \%$ and $95 \%$ indicates that photons initially absorbed by either PPV or PCBM can contribute to charge separation, i.e., routes $\mathrm{C}$ and $\mathrm{D}$ are both operative.

\section{The blend composition dependence}

Using relationship (11), we have determined the product of the quantum yield for charge carrier production $\phi$ and the mobility sum $\Sigma \mu$ from $\Delta G_{\mathrm{EOP}} / I_{0}$ values for transients obtained on irradiation at $500 \mathrm{~nm}$. Values of $\phi \Sigma \mu$ obtained for the separate components and the nine different blends investigated are listed in Table I and are plotted as a function of $W_{\text {PCBM }}$ in Fig. 5. The values given are for the lowest light intensity used, which allowed $\phi \Sigma \mu$ to be determined with an accuracy of $\pm 10 \%$. The influence of higher light intensities on the value of $\phi \Sigma \mu$ will be presented and discussed in a subsequent section.

As can be seen from the data in Table I, after an initial increase in $\phi \Sigma \mu$ in going from $W_{\mathrm{PCBM}}=0$ to 0.2 , the value of $\phi \Sigma \mu$ increases by only a factor of approximately 2 up to a PCBM content of $60 \%$. Above $60 \%$, however, a dramatic increase in $\phi \Sigma \mu$ occurs, by an order of magnitude at $70 \%$ PCBM, and by a further order of magnitude at $85 \%$ PCBM. Above $85 \%$ a slight decrease in $\phi \Sigma \mu$ occurs. However, even for $95 \%$ PCBM, $\phi \Sigma \mu$ is still two orders of magnitude larger than the average value found of approximately 0.6 $\times 10^{-3} \mathrm{~cm}^{2} / \mathrm{V} \mathrm{s}$ in the range between $20 \%$ and $60 \%$.

In discussing the possible reasons for the dramatic increase in $\phi \Sigma \mu$ above $W_{\mathrm{PCBM}}=0.6$ it is worth emphasizing that, because of the ultrahigh frequency of the probing microwaves in an FP-TRMC measurement, the microscopic mobility within organized domains is measured. A large TRMC photoconductivity does not therefore necessarily indicate a large bulk mobility since the latter will often be controlled more by the presence of domain boundaries and percolation pathways within the material rather than by the 

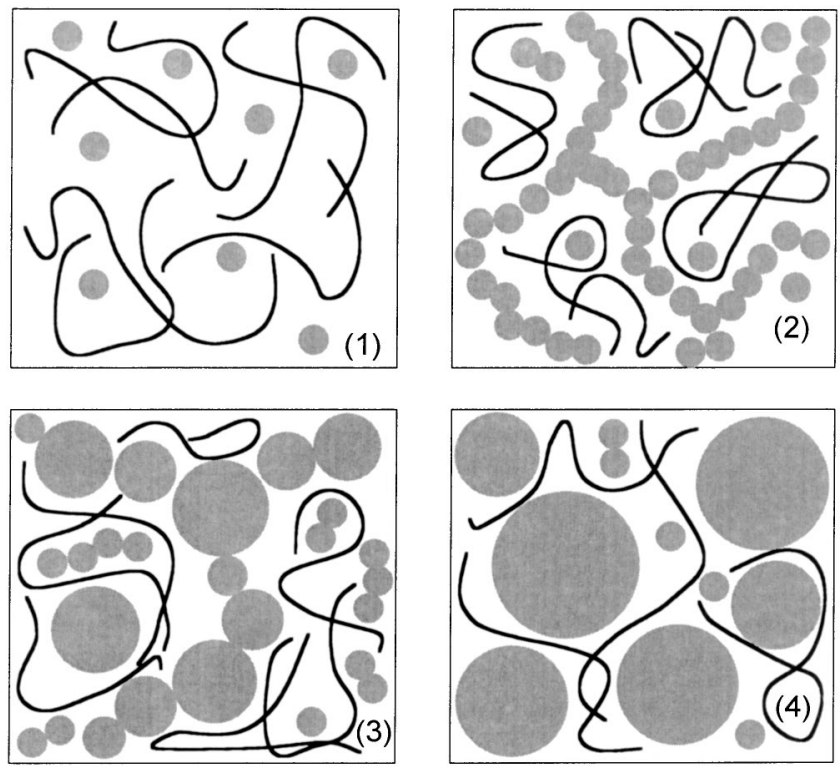

FIG. 6. Schematic representations of the blend morphology for $W_{\text {PCBM }}$ of approximately (a) $<0.2$, (b) $0.2-0.6$, (c) $0.6-0.8$, and (d) $>0.8$. The curved lines represent PPV polymers, the small circles represent individual PCBM molecules, and the larger circles represent phase-separated PCBM aggregates. The opening up of percolation pathways of PCBM molecules starts at $W_{\mathrm{PCBM}} \sim 0.2$. Above $W_{\text {PCBM }} \sim 0.6$, aggregation of PCBM molecules starts, followed by phase separation, resulting in the formation of large PCBM-rich domains embedded in the PPV/PCBM matrix, setting off at $W_{\text {PCBM }}>0.8$.

intrinsic mobility in organized domains of the components. Relating the present results to those found for PV device structures clearly requires, therefore, knowledge of the morphology of the blend layer.

Transmission electron microscopy (TEM) and atomic force microscopy (AFM) studies of MDMO-PPV/PCBM blends have shown that phase separation, with the formation of PCBM-rich aggregates, occurs above a given weight fraction of PCBM..$^{24,25,30-33}$ The critical concentration and size of the aggregates has been found to depend markedly on the method of film preparation, in particular on the solvent used. For layers spin-coated from chlorobenzene solutions, homogeneous films were found to be formed up to $W_{\text {PCBM }} \sim 0.6 .^{24,25,32,33}$ For $W_{\text {PCBM }}=0.8$, however, there was clear evidence of phase separation with the formation of large PCBM-rich aggregates. We discuss the results further, therefore, on the basis of Fig. 6, which is a much simplified pictorial representation of the changes occurring in the film morphology based on the TEM and AFM studies.

For low PCBM concentrations the film will consist of a homogeneous mixture of PPV chains and individual PCBM molecules, as shown in Fig. 6(a). Electron transfer between the components subsequent to photoexcitation will therefore result in the formation of holes on the polymer chains and electrons localized as PCBM radical anions. Since the negative charge is localized, the value of $\Sigma \mu$ would be expected to be determined mainly by the hole mobility and should be close to the value found for holes in bulk MDMO-PPV.
The hole mobility in freshly precipitated, solid MDMOPPV has been measured using the pulse-radiolysis TRMC technique (PR-TRMC) and found to be $1.8 \times 10^{-3} \mathrm{~cm}^{2} / \mathrm{V} \mathrm{s}{ }^{18}$ Combining this with the average value of $\phi \Sigma \mu$ of $0.6 \times 10^{-3} \mathrm{~cm}^{2} / \mathrm{V} \mathrm{s}$, determined in the $20 \%$ to $60 \%$ PCBM concentration range, results in an estimated quantum yield of mobile charge carriers of approximately $30 \%$. Fluorescence quenching measurements have indicated that the initial quantum yield of photoinduced charge separation is actually close to unity. ${ }^{34-37}$ It would appear, therefore, that a large fraction of the initially formed charge carriers in the present experiments must have undergone recombination or trapping on a time scale shorter than the response time of $18 \mathrm{~ns}$. We will return to this point in a subsequent section in which the decay kinetics of the photoconductivity transients are discussed.

The dramatic increase in $\phi \Sigma \mu$ above $W_{\mathrm{PCBM}}=0.6$ can be explained by the formation of PCBM-rich aggregates, $[\mathrm{PCBM}]_{n}$, within the blend, as observed in the TEM and AFM studies. In addition to the intermolecular charge transfer processes occurring in the homogeneous regions, reactions $\mathrm{C}$ and $\mathrm{D}$, electrons can now be formed within the aggregates by the interfacial electron transfer processes $\mathrm{E}$ and $\mathrm{F}$,

$$
\begin{aligned}
& \mathrm{PPV}^{*}[\mathrm{PCBM}]_{n} \longrightarrow \mathrm{PPV}^{+}[\mathrm{PCBM}]_{n}^{-} \quad(\text { reaction } \mathrm{E}), \\
& \mathrm{PPV}[\mathrm{PCBM}]_{n}^{*} \longrightarrow \mathrm{PPV}^{+}[\mathrm{PCBM}]_{n}^{-} \quad(\text { reaction } \mathrm{F}) .
\end{aligned}
$$

From PR-TRMC measurements on a bulk powder sample of C60 a mobility of $0.10 \mathrm{~cm}^{2} / \mathrm{V}$ s has been determined, ${ }^{20}$ in close agreement with the reported value of $0.08 \mathrm{~cm}^{2} / \mathrm{V} \mathrm{s}$ obtained by Hall measurements. ${ }^{19}$ This value is almost 2 orders of magnitude larger than the value of $\mu(+)$ found for MDMO-PPV. If a similar high mobility were applicable for electrons within the aggregated particles of PCBM, then this would explain the dramatic increase in $\phi \Sigma \mu$ observed. On the basis of a mobility of close to $0.1 \mathrm{~cm}^{2} / \mathrm{V} \mathrm{s}$, the maximum value of $0.083 \mathrm{~cm}^{2} / \mathrm{V}$ s found for $\phi \Sigma \mu$ in the $W_{\mathrm{PCBM}}=0.85$ sample indicates a quantum yield close to unity for the formation of mobile electrons within PCBM-rich aggregates.

In connection with the above, some points regarding the application of ultrahigh frequency conductivity detection techniques to the present phase-separated blends are worthy of note. Because of the low dielectric constant and insulating nature of the organic materials involved, the maximum amplitude of the electric field strength $\mathrm{E}$ will be close to uniform within the sample, including throughout the volume of the nanoparticles. For the low field strength used (approximately $10^{4} \mathrm{~V} / \mathrm{m}$ ) the potential drop across a length equal to the hopping distance of charge carriers (approximately $1 \mathrm{~nm}$ ) is very much less than $\mathrm{kT} / e$. The field therefore results in only a small perturbation of the random, thermal diffusive motion of a charge carrier. A decrease in the effective charge mobility, however, is expected to occur for a particle size L small enough that during the course of their diffusional motion, charge carriers encounter the surface of the particle on a time scale close to, or shorter than, the reciprocal radian frequency of the oscillating electric field $1 / \omega$. This corre- 
sponds to the condition $L \leqslant \sqrt{(6 D / \omega)}$ with $D$ the diffusion coefficient. For a mobility of $0.1 \mathrm{~cm}^{2} / \mathrm{V} \mathrm{s} \quad(D$ $\left.=0.0025 \mathrm{~cm}^{2} / \mathrm{s}\right)$ and a cyclic frequency of $9 \mathrm{GHz}(1 / \omega$ $=18 \mathrm{ps}$ ), as in the present case, the critical value of $\mathrm{L}$ is found to be approximately $5 \mathrm{~nm}$. This is substantially smaller than the estimated particle size of $15-40 \mathrm{~nm}$ determined by TEM for an $80 \%$ PCBM spin-coated film using chlorobenzene as solvent. A slight reduction in the effective (microwave) mobility compared with that in the bulk material, as mentioned in the previous paragraph, might, however, be expected.

\section{Comparison with the short-circuit current in device structures}

It is of interest to compare the dependence of $\phi \Sigma \mu$ on $W_{\text {PCBM }}$ with that found for the short-circuit current $I_{\mathrm{SC}}$, obtained for photovoltaic device structures based on similar spin-coated PCBM/MDMO-PPV layers. ${ }^{24,25}$ Such measurements are shown in Fig. 5. Though the $I_{\mathrm{SC}}$ values are not normalized to the overlap of the optical absorption and the lamp output, $I_{\mathrm{SC}}$ increases gradually above $W_{\mathrm{PCBM}} \approx 0.2$, reaches a maximum for $W_{\mathrm{PCBM}} \approx 0.75$, and decreases continuously above this concentration. This behavior is in marked contrast to the behavior found for $\phi \Sigma \mu$ described above. The difference cannot be ascribed to the different solvents used for spin-coating (chlorobenzene versus 1,2dichlorobenzene in the present work) since these solvents give almost identical FP-TRMC results (measurements to be published elsewhere).

The observation that the short-circuit current increases considerably in the same $W_{\text {PCBM }}$ regime where $\phi \Sigma \mu$ remains almost constant can be explained by the opening up of percolation pathways of PCBM molecules within the blend, which allow electron transport to occur over macroscopic distances via intermolecular electron transfer as shown in Figure 6(b). The lack of a significant, concomitant increase in $\phi \Sigma \mu$ indicates that the electron mobility within such pathways must be considerably lower than the value of approximately $1 \times 10^{-3} \mathrm{~cm}^{2} / \mathrm{V}$ s for holes within the polymer matrix. This is not necessarily in conflict with the observation of a photocurrent in device structures since a considerably lower electron mobility than $1 \times 10^{-3} \mathrm{~cm}^{2} / \mathrm{V}$ s would still be sufficient to explain the currents observed.

The apparent anomaly that the short-circuit current in device structures does not display an abrupt increase in the same concentration range as that found for $\phi \Sigma \mu$ can be understood if the formation of PCBM aggregates results in a decrease, rather than an increase, in percolation pathways as illustrated in Fig. 6(c). The TEM images do in fact show that the PCBM aggregates are well defined and are surrounded by a matrix of polymer-rich material. ${ }^{24,25,33}$ This would be expected to present a barrier towards electron transfer between the individual PCBM particles and hence have a negative influence on bulk charge transport. Percolation pathways should, however still be present within the homogeneously mixed regions of the blend, which would be expected to contain a weight fraction of PCBM molecules of close to $60 \%$, i.e., the composition just prior to the occurrence of

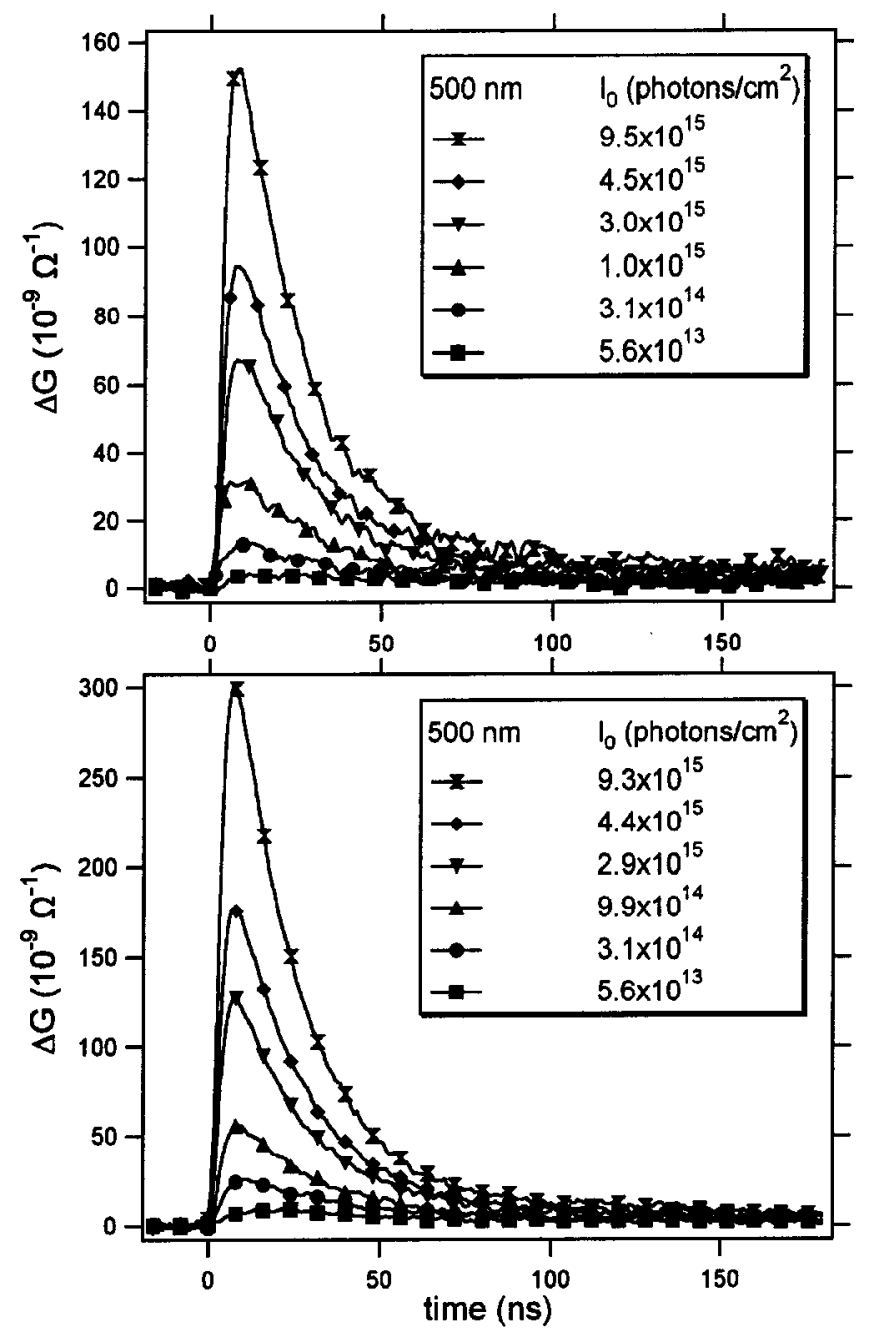

FIG. 7. Photoconductivity transients obtained on $500 \mathrm{~nm}$ flashphotolysis of a film with $W_{\mathrm{PCBM}}=0.2$ (upper panel) and 0.6 (lower panel) for different incident light intensities in the pulse.

aggregation. Detailed theoretical and morphological studies should provide further evidence for this hypothesis. Because of the extremely high molecular weight of MDMO-PPV and its fibrous nature, percolation pathways for hole transport would be expected to be present even for very low fractional concentrations of the polymer.

In view of the above, we conclude that the two sets of data, which at first sight appear to be in conflict, can in fact be reconciled. Furthermore, the combination of the two provides a more detailed insight into the photophysics of charge separation in these complex materials.

\section{E. After-pulse decay kinetics}

Since the magnitude of a TRMC transient is determined by the major, i.e., most mobile, charge carrier, we conclude, on the basis of the above, that for values of $W_{\text {PCBM }}$ up to 0.6 we are monitoring mainly the formation and decay of mobile holes on the PPV polymer chains, $\mathrm{PPV}^{+}$. For $W_{\mathrm{PCBM}}=0.7$ and above, however, the transients observed will be governed mainly by the formation and decay of the highly mobile electrons within PCBM aggregates, $[\mathrm{PCBM}]_{n}$. 


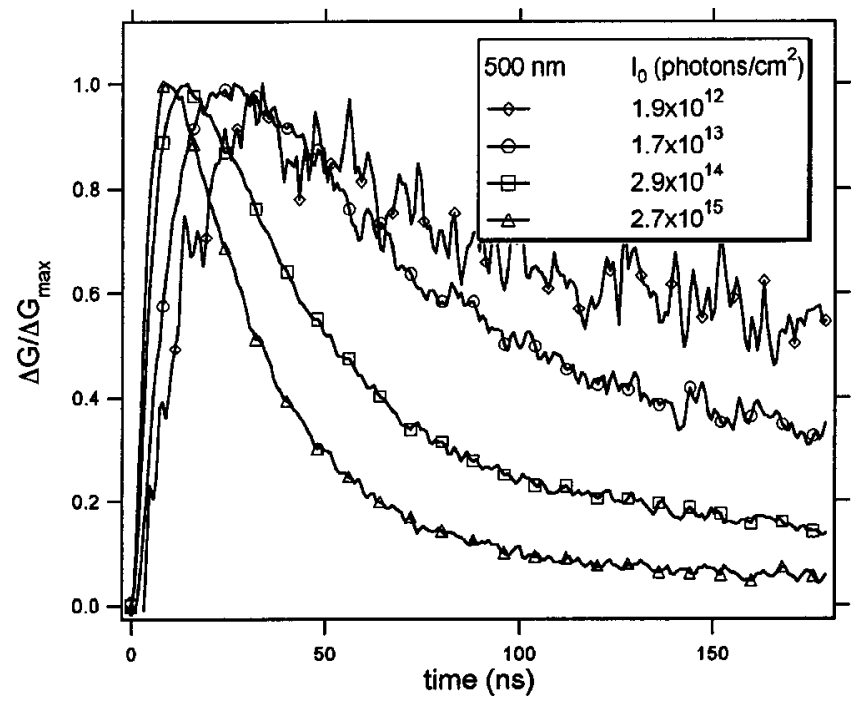

FIG. 8. Photoconductivity transients obtained on $500 \mathrm{~nm}$ flashphotolysis of a film with $W_{\text {PCBM }}=0.8$ for different incident light intensities in the pulse. The transients, which have been normalized to the same maximum value of $\Delta G$, illustrate second order recombination of the charge carriers to be important.

In Fig. 7 conductivity transients are shown for $W_{\text {PCBM }}$ $=0.2$ (upper) and 0.6 (lower) with incident light intensities varying from approximately $5 \times 10^{13}$ to approximately 1 $\times 10^{16}$ photons $/ \mathrm{cm}^{2} /$ pulse at $500 \mathrm{~nm}$. The absolute magnitude and temporal form of the transients are seen to be closely similar for the two PCBM weight fractions. We conclude that the yield of holes and their mechanism of decay remain almost unchanged over this concentration range. In this regard it is worth pointing out that even for $W_{\mathrm{PCBM}}$ $=0.6$ more than $80 \%$ of the photons are initially absorbed by the polymer.

The after-pulse decay occurs with a first half-life of approximately $20 \mathrm{~ns}$, which is close to the instrumental time response. This indicates that a substantial fraction of the charge carriers will in fact have decayed within this time. The values of $\phi \Sigma \mu$ derived from $\Delta G_{\mathrm{EOP}} / I_{0}$ values will therefore be substantially lower than the initial value of $\phi_{0} \Sigma \mu$. This is in agreement with the conclusion made previously that only approximately $30 \%$ of the initially formed charge carriers are present on the time scale of the measurements. That a large fraction of the initially formed ion pairs undergo (geminate) charge recombination on a (sub)nanosecond time scale is in agreement with a picosecond timeresolved infrared study of $\mathrm{MEH}-\mathrm{PPV} / \mathrm{C}_{60}$ composites in which the first half-life of the initial ion pairs was found to be approximately $0.5 \mathrm{~ns}^{37}$

In contrast with the almost intensity-independent afterpulse decay kinetics found in the $20 \%$ to $60 \%$ PCBM concentration range, the decay of transients at higher PCBM concentrations is found to be markedly dependent on intensity. This is illustrated for the $W_{\text {PCBM }}=0.8$ sample in Fig. 8 where the transients have been normalized to the same maximum value in order to emphasize the changes occurring in the after-pulse decay kinetics. While the initial decay is controlled mainly by the instrument response time of $18 \mathrm{~ns}$ for the highest intensity, for the lowest intensity the first half-life is much longer with a value of approximately $150 \mathrm{~ns}$. Similar results were found for all samples with $W_{\text {PCBM }}=0.75$ and higher. Clearly, second-order charge recombination plays an important role in the decay of the photoconductivity for the high PCBM content blends.

Since the large conductivity transients observed for the high PCBM content blends are attributed to highly mobile electrons within PCBM-rich aggregates, we explain the intensity dependence of the decay kinetics as follows. Photoexcitations produced within a PCBM-rich aggregate or a vicinal PPV chain segment undergo electron transfer at the surface of the particle. The electrons formed diffuse within the aggregate and eventually undergo interfacial charge recombination with a $\mathrm{PPV}^{+}$hole at the surface. In order to explain the second-order nature of the decay, more than one electron per PCBM particle must be produced during the pulse and recombination must occur with a hole other than the geminate partner formed in the initial electron transfer process. A primary requirement is, therefore, that more than one photon must be absorbed within a particle or a neighboring PPV chain.

An approximate estimate of the average number of photons absorbed per PCBM particle, $n_{\mathrm{pp}}$, for particles of dimension $d \mathrm{~nm}$ is given by the relationship,

$$
n_{\mathrm{pp}} \approx 10^{-23} \alpha_{\mathrm{PCBM}} I_{0} d^{3}
$$

for $d$ considerably smaller than the penetration depth and $I_{0}$ the number of incident photons per $\mathrm{cm}^{2}$ per pulse, as defined previously. The condition for multiple electron formation within particles is therefore given by

$$
I_{0}>10^{23} / \alpha_{\mathrm{PCBM}} d^{3} \text {. }
$$

Substituting for $\alpha_{\mathrm{PCBM}}=2.77 \times 10^{6} \mathrm{~m}^{-1}$ in Eq. (17) and taking for $d$ a value of approximately $10 \mathrm{~nm}$, as indicated by the TEM and AFM results, ${ }^{32}$ suggests that effects due to second-order charge recombination should begin to be observed for intensities close to $4 \times 10^{13}$ photons $/ \mathrm{cm}^{2} /$ pulse. This is in agreement with the after-pulse decays shown in Fig. 8 for which the first half-life decreases from $150 \mathrm{~ns}$ for the lowest intensity $\left(1.9 \times 10^{12}\right.$ photons $/ \mathrm{cm}^{2} /$ pulse $)$ to 75 and $30 \mathrm{~ns}$ for intensities of $1.7 \times 10^{13}$ and 2.9 $\times 10^{14}$ photons $/ \mathrm{cm}^{2} /$ pulse, respectively. We consider that this supports the mechanism proposed.

Durrant et al. ${ }^{38,39}$ have carried out a transient opticalabsorption study of a $W_{\mathrm{PCBM}}=0.8$ blend layer, prepared in a similar way to that used in the present study and irradiated under closely similar conditions of pulse width and time resolution (approximately $20 \mathrm{~ns}$ ). The optical-absorption transients observed in that work, for the same excitation wavelength $(500 \mathrm{~nm})$ and similar intensities to those in Fig. 8 , resembled more closely the TRMC transients found in the present work for the $20 \%$ to $60 \%$ PCBM range rather than the $80 \%$ PCBM TRMC transients shown in Fig. 8, i.e., the first half-life was almost intensity-independent and close to the instrumental time response of approximately $20 \mathrm{~ns}$.

We consider that the difference between the optical absorption and TRMC results lies in the fact that in the former 


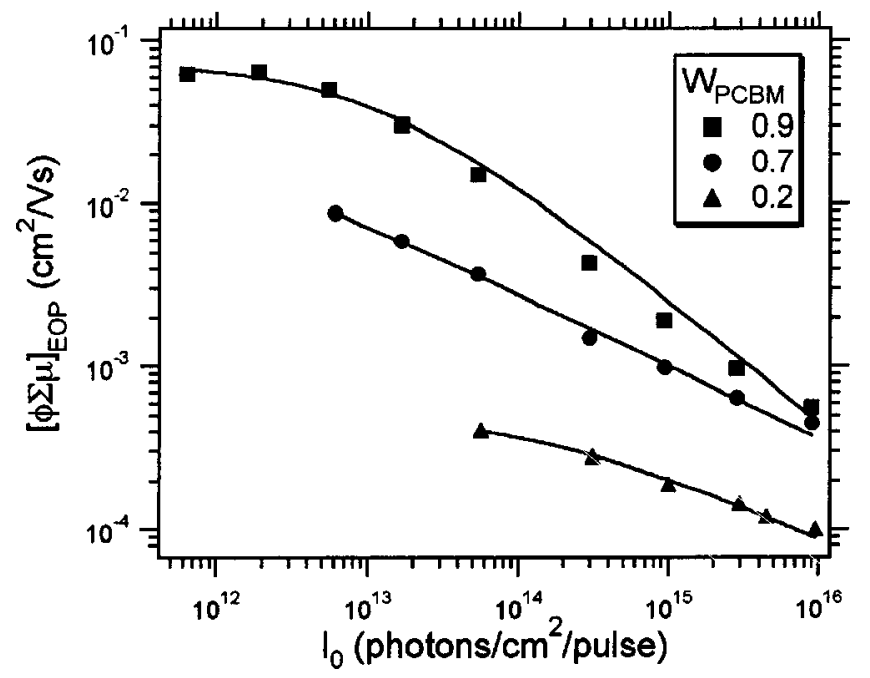

FIG. 9. The intensity dependence of the product of the quantum efficiency for charge separation $\phi$ and the sum of the charge carrier mobilities $\Sigma \mu$ derived from the $\Delta G_{\mathrm{EOP}}$ values for $500 \mathrm{~nm}$ flashphotolysis of films with $W_{\text {PCBM }}$ values of 0.2 (triangles), 0.7 (circles), and 0.9 (squares).

the PPV hole was being monitored while the latter monitors the electron in the PCBM aggregates. In this regard it is worth noting that, even for $80 \%$ by weight of PCBM, more than $60 \%$ of the light is absorbed by the PPV component according to Eq. (15b). In addition, the MDMO-PPV-rich regions would still be expected to contain approximately $60 \%$ by weight of PCBM as single molecules. The main contribution to the optical-absorption transients will therefore arise from $\mathrm{PPV}^{+} / \mathrm{PCBM}^{-}$pairs which would be expected to have similar decay kinetics to those observed using the TRMC technique in the $20 \%$ to $60 \%$ PCBM concentration range, as is in fact found.

\section{F. The intensity dependence of $\phi \Sigma \mu$}

As mentioned previously, the values of $\phi \Sigma \mu$ presented in Fig. 5 were derived from the maximum transient change in conductance, $\Delta G_{\mathrm{EOP}}$, for the lowest light intensity used for a particular value of $W_{\text {PCBM }}$. In all cases the value of $\phi \Sigma \mu$ was found to decrease at higher intensities. This is illustrated for $W_{\text {PCBM }}=0.2,0.7$, and 0.9 in Fig. 9.

For $W_{\mathrm{PCBM}}=0.9, \phi \Sigma \mu$ is seen to approach a constant value at the lowest intensities. When this is taken together with the fact that the decay after the pulse is considerably longer than the instrument response time for the lowest intensities, we conclude that the value of $\phi$ under these circumstances represents the initial quantum yield for charge carrier formation $\phi_{0}$. This is in agreement with the conclusion in a previous section that $\phi$ must be close to unity based on the expected mobility of electrons in PCBM aggregates of close to $0.1 \mathrm{~cm}^{2} / \mathrm{V} \mathrm{s}$.

As can be seen from the transients in Fig. 8, the afterpulse decay rate increases with increasing intensity for a high $W_{\text {PCBM }}$ sample. For the highest intensities the first half-life of the decay becomes comparable with the response time indicating that a fraction of the mobile carriers will in fact have decayed within this time. This explains, at least in part, the gradual decrease in $\phi \Sigma \mu$ for intensities in excess of approximately $1 \times 10^{13}$ photons $/ \mathrm{cm}^{2} /$ pulse. Convolution fits to the transients indicate, however, that this effect is insufficient to completely explain the magnitude of the decrease observed. We suggest that an additional second-order process occurs within the pulse, which competes with charge carrier formation. This could be due to the occurrence of exciton-exciton annihilation or to the increasing overlap of the Onsager spheres of the electron hole pairs formed on charge transfer. We can, however, not completely exclude the possibility that strongly absorbing excited states or ionic products of photolysis preferentially absorb light in competition with the primary excitation processes $\mathrm{A}$ and $\mathrm{B}$.

For $W_{\mathrm{PCBM}} \approx 0.7$ and lower, a constant value of $\phi \Sigma \mu$ is not approached even for the lowest intensities used. The corresponding value of $\phi$ must therefore be lower than $\phi_{0}$ as deduced in previous sections based on the mobility of holes in MEH-PPV and the fact that the after-pulse decay occurs on a time scale comparable with the instrument response time. The fact that the decay kinetics for the lower PCBM concentrations, shown in Fig. 7, are almost independent of intensity suggests that the decrease in $\phi \Sigma \mu$ with intensity observed is due to rapid second order processes occurring within the pulse or to filtering by photoproducts as suggested above for the higher values of $W_{\text {PCBM. }}$

\section{CONCLUSIONS}

The formation and decay of mobile charge carriers on nanosecond pulsed photoexcitation of spin-coated layers of blends of highly soluble derivatives of C60 (PCBM) and poly(phenylene vinylene) (MDMO-PPV) have been studied using the flash-photolysis time-resolved microwave conductivity technique (FP-TRMC). Measurements have been made for nine blend compositions with PCBM weight fractions, $W_{\text {PCBM }}$, varying from 0.2 to 0.95 , as well as for the separate components.

The optical-absorption spectra of the blends can be reconstructed from those of the separate components with no indication of additional absorption bands attributable to direct transitions to charge transfer states. Charge separation via electron transfer yielding MDMO-PPV ${ }^{+}$and $\mathrm{PCBM}^{-}$subsequent to photoexcitation is evidenced by a large increase in the photoconductivity in the blend layers compared with that found for layers of the pure components alone. The wavelength dependence of the incident intensity-normalized photoconductivity, $\Delta G_{\mathrm{EOP}} / I_{0}$, closely resembles the spectral dependence of the fraction of photons absorbed over the range 420-700 $\mathrm{nm}$. We conclude that electron transfer can occur between the components irrespective of whether PPV or PCBM is initially photoexcited.

The product of the quantum yield and the sum of the mobilities of the charge carriers formed, $\phi \Sigma \mu$, determined from the end-of-pulse conductivity at $500 \mathrm{~nm}$, changes little in going from $W_{\mathrm{PCBM}}=0.2$ to 0.6 . The average value of $\phi \Sigma \mu$ over this range (approximately $0.6 \times 10^{-3} \mathrm{~cm}^{2} / \mathrm{V} \mathrm{s}$ ) is lower than the value of $1.8 \times 10^{-3} \mathrm{~cm}^{2} / \mathrm{V} \mathrm{s}$ determined for the mobility of holes in bulk MDMO-PPV using the pulse- 
radiolysis microwave conductivity technique (PR-TRMC). [Ref. 18]. We conclude that a substantial fraction of the initially formed charge carriers have decayed within the instrument response time of $18 \mathrm{~ns}$. Above $W_{\mathrm{PCBM}} \approx 0.6, \phi \Sigma \mu$ increases dramatically up to a maximum value of approximately $80 \times 10^{-3} \mathrm{~cm}^{2} / \mathrm{V} \mathrm{s}$ for $W_{\mathrm{PCBM}}=0.85$, i.e., more than two orders of magnitude larger than found in the 0.2 to 0.6 composition range. We attribute this increase to the occurrence of phase separation and the formation of highly mobile electrons in PCBM aggregates. The value of $\phi \Sigma \mu$ is found to decrease above an incident intensity of approximately $1 \times 10^{13}$ photons $/ \mathrm{cm}^{2}$ per pulse for all blend compositions. This is attributed to the occurrence of exciton-exciton annihilation and/or overlap of the Onsager spheres of the electron hole pairs formed on charge transfer.

In the $20 \%$ to $60 \%$ PCBM composition range the afterpulse decay of the conductivity, which is attributed mainly to mobile holes within the PPV component, occurs on a time scale close to the time resolution of the measurements, i.e., over a few tens of nanoseconds. Within this range of composition, the decay rate is relatively insensitive to the incident intensity. For $W_{\mathrm{PCBM}}>0.75$ the conductivity, which in this case is attributed mainly to mobile electrons within PCBM aggregates, displays much longer lifetimes of close to $200 \mathrm{~ns}$ for the lowest light intensities used. In contrast with the observations for $W_{\mathrm{PCBM}} \leqslant 0.6$, the after-pulse decay rate in the high PCBM content region is found to increase markedly with increasing intensity. This is attributed to the occurrence of second-order recombination of electrons with holes at the PCBM-particle/PPV interface.

The present FP-TRMC results have been compared with short-circuit current measurements on photovoltaic device structures based on closely similar blend layers. ${ }^{24}$ These show that $\mathrm{I}_{\mathrm{SC}}$ increases substantially over the range of $W_{\mathrm{PCBM}}$ within which $\phi \Sigma \mu$ is found to remain almost constant, and actually begins to decrease in the range where $\phi \Sigma \mu$ displays a dramatic increase. This apparent contradiction is explained by the gradual formation of percolation pathways between individual PCBM molecules in the region where homogeneous blend layers are formed, i.e., less than approximately $60 \%$ PCBM. This allows the bulk transport of electrons via intermolecular electron transfer. The effective electron mobility via percolation is, however, still much lower than that of holes within the PPV component. In the higher PCBM content layers the occurrence of aggregation, to form large, isolated particles consisting (mainly) of PCBM, reduces the number of percolation pathways and hence the possibility of bulk transport of electrons. The combined results illustrate, therefore, the difference between the methods of investigation, with photovoltaic measurements providing information on bulk charge transport between the electrodes and FP-TRMC providing information on the mobility of charge carriers within microscopic domains of the blend layers. The two methods together therefore provide a more detailed insight into the influence of morphology on the photophysics of charge separation and transport in these potentially important types of photovoltaic materials.

\section{ACKNOWLEDGMENTS}

The authors wish to thank J.K.J. Van Duren and Professor R.A.J. Janssen (TU Eindhoven) for making available their short-circuit data prior to publication. The research was supported financially by the Netherlands Organization for Scientific Research (NWO).
*Email address: Tom.Savenije@ IRI.TUDelft.NL

†resent address: Laboratory of Macromolecular and Organic Chemistry, Eindhoven University of Technology, P.O. Box 513, 5600 MB Eindhoven, The Netherlands.

${ }^{1}$ J. J. Halls and R. H. Friend, in Clean Electricity from Photovoltaics, edited by M. D. Archer and R. Hill (Imperial College Press, London, 2001).

${ }^{2}$ M. Gratzel, Nature (London) 414, 338 (2001).

${ }^{3}$ C. J. Brabec and N. S. Sariciftci, in Semiconducting Polymers, edited by G. Hadziioannou and P. van Hutten (Wiley-VCH, Weinheim, 2000), p. 515.

${ }^{4}$ N. S. Sariciftci, D. Braun, C. Zhang, V. I. Srdanov, A. J. Heeger, G. Stucky, and F. Wudl, Appl. Phys. Lett. 62, 585 (1993).

${ }^{5}$ S. Morita, S. B. Lee, A. A. Zakhidov, and K. Yoshino, Mol. Cryst. Liq. Cryst. Sci. Technol., Sect. A 256, 839 (1994).

${ }^{6}$ J. J. M. Halls, K. Pichler, R. H. Friend, S. C. Moratti, and A. B. Holmes, Synth. Met. 77, 277 (1996).

${ }^{7}$ T. J. Savenije, J. M. Warman, and A. Goossens, Chem. Phys. Lett. 287, 148 (1998).

${ }^{8}$ L. A. A. Pettersson, L. S. Roman, and O. Inganas, J. Appl. Phys. 86, 487 (1999).

${ }^{9}$ G. Yu, J. Gao, J. C. Hummelen, F. Wudl, and A. J. Heeger, Science 270, 1789 (1995).

${ }^{10}$ N. S. Sariciftci, Prog. Quantum Electron. 19, 131 (1995).

${ }^{11}$ S. E. Shaheen, C. J. Brabec, N. S. Sariciftci, F. Padinger, T. From- herz, and J. C. Hummelen, Appl. Phys. Lett. 78, 841 (2001).

${ }^{12}$ C. J. Brabec, S. E. Shaheen, C. Winder, N. S. Sariciftci, and P. Denk, Appl. Phys. Lett. 80, 1288 (2002).

${ }^{13}$ F. Padinger, R. S. Rittberger, and N. S. Sariciftci, Adv. Funct. Mater. 13, 85 (2003).

${ }^{14}$ J. M. Kroon, M. M. Wienk, W. J. H. Verhees, and J. C. Hummelen, Thin Solid Films 403, 223 (2002).

${ }^{15}$ C. J. Brabec, S. E. Shaheen, T. Fromherz, F. Padinger, J. C. Hummelen, A. Dhanabalan, R. A. J. Janssen, and N. S. Sariciftci, Synth. Met. 121, 1517 (2001).

${ }^{16}$ H. C. F. Martens, P. W. M. Blom, and H. F. M. Schoo, Phys. Rev. B 61, 7489 (2000).

${ }^{17}$ H. C. F. Martens, O. Hilt, H. B. Brom, P. W. M. Blom, and J. N. Huiberts, Phys. Rev. Lett. 87, 086601 (2001).

${ }^{18}$ J. M. Warman, G. H. Gelinck, and M. P. de Haas, J. Phys.: Condens. Matter 14, 9935 (2002).

${ }^{19}$ R. C. Haddon, A. S. Perel, R. C. Morris, T. T. M. Palstra, A. F. Hebard, and R. M. Fleming, Appl. Phys. Lett. 67, 121 (1995).

${ }^{20}$ R. J. O. M. Hoofman, G. P. van der Laan, M. P. de Haas, and K. Tanigaki, Synth. Met. 86, 2355 (1997).

${ }^{21}$ V. D. Mihailetchi, J. K. J. van Duren, P. W. M. Blom, J. C. Hummelen, R. A. J. Janssen, J. M. Kroon, M. T. Rispens, W. J. H. Verhees, and M. M. Wienk, Adv. Funct. Mater. 13, 43 (2003).

${ }^{22}$ L. C. Chen, D. Godovsky, O. Inganas, J. C. Hummelen, R. A. J. Janssen, M. Svensson, and M. R. Andersson, Adv. Mater. (Weinheim, Ger.) 12, 1367 (2000). 
${ }^{23}$ J. Gao, F. Hide, and H. L. Wang, Synth. Met. 84, 979 (1997).

${ }^{24}$ J. K. J. van Duren, X. Yang, J. Loos, C. W. T. Bulle-Lieuwma, A. B. Sieval, J. C. Hummelen, and R. A. J. Janssen, Proc. SPIE (to be published).

${ }^{25}$ J. K. J. van Duren, X. Yang, J. Loos, C. W. T. Bulle-Lieuwma, A. B. Sieval, J. C. Hummelen, and R. A. J. Janssen, Adv. Funct. Mater. (to be published).

${ }^{26}$ C. J. Brabec, F. Padinger, N. S. Sariciftci, and J. C. Hummelen, J. Appl. Phys. 85, 6866 (1999).

${ }^{27}$ J. E. Kroeze, T. J. Savenije, M. J. W. Vermeulen, and J. M. Warman, J. Phys. Chem. B 107, 7696 (2003).

${ }^{28}$ B. R. Wegewijs, G. Dicker, J. Piris, A. A. Garcia, M. P. de Haas, and J. M. Warman, Chem. Phys. Lett. 332, 79 (2000).

${ }^{29}$ M. P. de Haas and J. M. Warman, Chem. Phys. 73, 35 (1982).

${ }^{30}$ L. S. Roman, M. R. Andersson, T. Yohannes, and O. Inganas, Adv. Mater. 9, 1110 (1997).

${ }^{31}$ J. Liu, Y. J. Shi, and Y. Yang, Adv. Funct. Mater. 11, 420 (2001).

${ }^{32}$ T. Martens, J. D’Haen, T. Munters, Z. Beelen, L. Goris, J. Manca, M. D'Olieslaeger, D. Vanderzande, L. De Schepper, and R. An- driessen, Synth. Met. 138, 243 (2003).

${ }^{33}$ T. Martens, Z. Beelen, J. D’Haen, T. Munters, L. Goris, J. Manca, M. D'Olieslaeger, D. Vanderzande, L. De Schepper, and R. Andriessen, Proc. SPIE 4801, 40 (2003).

${ }^{34}$ S. Morita, A. A. Zakhidov, and K. Yoshino, Solid State Commun. 82, 249 (1992).

${ }^{35}$ B. Kraabel, J. C. Hummelen, D. Vacar, D. Moses, N. S. Sariciftci, A. J. Heeger, and F. Wudl, J. Chem. Phys. 104, 4267 (1996).

${ }^{36}$ D. Moses, A. Dogariu, and A. J. Heeger, Phys. Rev. B 61, 9373 (2000).

${ }^{37}$ S. C. J. Meskers, P. A. van Hal, A. J. H. Spiering, J. C. Hummelen, A. F. G. van der Meer, and R. A. J. Janssen, Phys. Rev. B 61, 9917 (2000).

${ }^{38}$ A. F. Nogueira, I. Montanari, J. Nelson, J. R. Durrant, C. Winder, and N. S. Sariciftci, J. Phys. Chem. B 107, 1567 (2003).

${ }^{39}$ I. Montanari, A. F. Nogueira, J. Nelson, J. R. Durrant, C. Winder, M. A. Loi, N. S. Sariciftci, and C. Brabec, Appl. Phys. Lett. 81, 3001 (2002). 